\title{
Fine-Structure Mapping of Meiosis-Specific Double-Strand DNA Breaks at a Recombination Hotspot Associated With an Insertion of Telomeric Sequences Upstream of the HIS4 Locus in Yeast
}

\author{
Fei Xu and Thomas D. Petes \\ Department of Biology and Curriculum in Genetics and Molecular Biology, University of North Carolina, \\ Chapel Hill, North Carolina 27599-3280 \\ Manuscript received January 2, 1996 \\ Accepted for publication March 25, 1996
}

\begin{abstract}
Meiotic recombination in Sacharomyces cerevisiae is initiated by double-strand DNA breaks (DSBs). Using two approaches, we mapped the position of DSBs associated with a recombination hotspot created by insertion of telomeric sequences into the region upstream of HIS4. We found that the breaks have no obvious sequence specificity and localize to a region of $\sim 50 \mathrm{bp}$ adjacent to the telomeric insertion. By mapping the breaks and by studies of the exonuclease III sensitivity of the broken ends, we conclude that most of the broken DNA molecules have blunt ends with 3 '-hydroxyl groups.
\end{abstract}

$\mathrm{C}$ YERTAIN regions of the Saccharomyces cerevisiae ge1 nome have unusually high levels of meiotic recombination (reviewed by PETES et al. 1991; LiCHTEN and GOLDMAN 1995). Such hotspots are associated with elevated levels of meiosis-specific double-strand breaks (DSBs). DSBs, initially described at the ARG4 locus (SUN et al. 1989), have been associated with many other recombination hotspots in yeast (CAO et al. 1990; ZENFIRTH et al. 1992; DE MASSY and NiCOLAS et al. 1993; GAME 1993), including HIS4 (NAG and PETES 1993; FAN et al. 1995). Several lines of evidence indicate that the DSBs are likely to be the lesion responsible for the initiation of meiotic recombination. First, the level of DSB is proportional to the recombination frequency at the ARG4 (DE MASSY and NICOLAS 1993) and HIS4 (FAN et al. 1995) loci. Second, DSBs occur at a time in meiosis consistent with a role as an initiator of recombination (PADMORE et al. 1991). Third, the position of the DSB corresponds to the region of highest recombination activity, the peak of the polarity gradient of gene conversion (Sun et al. 1989; NAG and PeTes 1993).

Hotspots of recombination in yeast are usually located between rather than within genes (PETES et al. 1991). The rules governing the position and intensity of the DSBs have not yet been established. Two types of experiments indicate that chromatin structure is likely to be important. First, hotspot activity and DSB formation at the HIS4 locus requires binding of transcription factors (WHITE et al. 1991, 1993; FAN et al. 1995), although a high rate of transcription is not required for hotspot activity (WHITE et al. 1992). Second, most DSBs occur in chromosomal regions that are sensitive to DNase I or micrococcal nuclease (OHTA et al. 1994; Wu and Lichten 1994; FAN and Petes 1996).

\footnotetext{
Corresponding author: Thomas D. Petes, Department of Biology, University of North Carolina, Chapel Hill, NC 27599-3280.

E-mail: tompetes@email.unc.edu
}

In wild-type yeast cells, the ends resulting from DSBs are degraded $5^{\prime}$ to $3^{\prime}$, resulting in $3^{\prime}$ single-stranded "tails" (SUN et al. 1991). In strains containing the rad50S mutation, this degradation does not occur, facilitating the mapping of DSBs (CAO et al. 1990). Using rad50S strains, three groups have done fine-structure mapping of DSBs associated with the following recombination hotspots: ARG4 and YCR74c-YCR48w (LIU et al. 1995), HIS4/LEU2 (XU and KLECKNER 1995), and CYS3 (DE MASSY et al. 1995). These mapping experiments showed that the DSBs were spread over regions of 70$200 \mathrm{bp}$ and that break sites had no obvious sequence specificity. A covalent attachment of the $5^{\prime}$ strand of the broken DNA end to a protein was also observed (DE MASSY $e t$ al. 1995; KEENEY and KLECKNER 1995; LiU et al. 1995). The nature of the broken end in these studies is controversial. Whereas LiU et al. (1995) found that the termini had a two base $5^{\prime}$ overhang, DE MASsY et al. (1995) concluded that the ends were blunt. The results of XU and KLECKNER (1995) are most consistent with termini with a 4-6-bp $5^{\prime}$ overhang.

WhITE et al. (1993) showed that an insertion of telomeric DNA upstream of the HIS4 gene created a very strong recombination hotspot. This hotspot was associated with a high level of DSB near the site of the telomeric insertion (FAN et al. 1995). Below, we describe the fine-structure mapping of the DSBs associated with this hotspot. We conclude the following: (1) DSBs are formed with blunt ends, (2) the DSBs occur in a 50bp region adjacent to (but not within) the telomeric sequences, and (3) at least some of the 3 ' termini associated with the broken ends have a hydroxyl group.

\section{MATERIALS AND METHODS}

Strains and plasmids: The diploid yeast strain FX4 used for mapping DSB sites had the following genotype (FAN et al. 
1995): $\alpha / a$ his4-202/his4-202 his4-lopc/HIS4 rad50S/ rad50S trp1/TRP1 arg4/ARG4 tyr7/TYR7 LEU2/leu2 ade6/ade6. The his 4-lopc allele is a mutation caused by insertion of a palindromic oligonucleotide (NAG et al. 1989). The homozygous his4-202 allele is a 50-bp telomeric sequence inserted upstream of HIS4 that creates a strong recombination hotspot (WHITE et al. 1993). The plasmid pMW50 (WHITE et al. 1993) has a Sau3Al fragment (containing the HIS4 upstream region with the his4-202 subsitution, Figure 1) inserted into the BamHI site of B142 (a Ylp5 derivative lacking the PvuII site). Plasmids pDN42 [Xhol-BglI HIS4 fragment inserted in XhoI/ BamHI-treated BluescriptII SK(-) (NAG and PETES 1993)] and pFX2b [Sau3A fragment containing normal BIK1-HIS4 intergenic region inserted in the BamHI site of the vector (Stratagene Cloning Systems) BluescriptII SK(-)] were used as hybridization probes (Figure 1).

Yeast DNA isolation and Southern analysis of DNA fragments separated by agarose gel electrophoresis: Yeast genomic DNA was prepared as described previously (NAG and PETES 1993). Meiotic DNA was isolated from cells collected after $24 \mathrm{hr}$ incubation in sporulation medium; this time point was chosen based on previous studies of the kinetics of DSB formation in FX4 (FAN et al. 1995). DNA derived from meiotic cells was treated with $E c o$ RI, and DNA derived from mitotic cells was treated with EcoRI and PvuII or EcoRI and BbsI. The resulting fragments were separated by agarose gel electrophoresis, transferred to a Hybond $\mathrm{N}+$ membrane (Amersham), and hybridized to an EcoRI-Xhol fragment derived from pDN42 (Figure 1).

Two-dimensional agarose gel electrophoresis was done as described by LIU et al. (1995). Meiotic DNA samples (treated with $B g I I$ ) were run in the first dimension using standard conditions. Gels were then soaked twice for $40 \mathrm{~min}$ in $50 \mathrm{mM}$ $\mathrm{NaOH}, 1 \mathrm{mM}$ EDTA, rotated $90^{\circ}$, and run in alkaline buffer (50 mM NaOH, $1 \mathrm{mM} \mathrm{EDTA).} \mathrm{The} \mathrm{separated} \mathrm{DNA} \mathrm{fragments}$ were transferred to Hybond-N+ and hybridized to labeled pDN42 DNA.

Oligonucleotides used for PCR, primer extension and sequencing: In addition to an identifying number and the sequence of the oligonucleotides, we indicate (in parentheses) whether the sequences are derived from vector or the $B I K l$ or HIS4 region. The number in parentheses represents the position of the $5^{\prime}$ base of the oligonucleotide within the BgII fragment containing the $B I K l$ and $H I S 4$ gene, with +1 representing the first base in the $B g I I$ site in $B I K l$; the GenBank accession number for the sequences between the BIKI Sad and the HIS4 BgIII restriction sites (Figure 1) is V01310. Oligonucleotides 10083, 10193, 10918 and 10929 were used in the primer extension experiments and had $5^{\prime}$ ends located at $(10083,10193)$ or one base pair displaced $(10929,10918)$ from $B s t \mathrm{UI}$ or HaelII sites, as indicated.

\section{3, AGCGGATAACAATTTCACACAGG (Bluescript II $\mathrm{SK}(-))$}

7278, GGGAATTCCCCCCCCCCCCCCCCCCCC

7492, CGCGGATCCCACTGGTGCGAAGGAAGATGTCG (BIK1, 595)

7680, CGCGGATCCATCCAAAAGTACCTGACCAACAAG (HIS4, 1287)

7981, CAGCTGGAACAATTACGCAACATAG $(B I K 1,634)$

7982, CGTATTCCTTCTTACTATTCCATGAG (HIS4, 1256)

8172, ATCGCAATGCTCACACCACTG (BIK1, 960)

9905, TATGAACAGTAGTATACTGTGT (HIS4, 1049)

10083, CGAACAATTGAAAATGGATAACGATTCG (BIK1, $B s t \mathrm{UI}, 702)$

10193, CGAGATCATCAATTAACGGTAGAATCGG (HIS4, HaeIII, 1229)

10918, GAACAATTGAAAATGCATAACGATTCG (BIK1, $B s t \mathrm{UI}+1,703$ )
10929, CAGATCATCAATTAACGGTAGAATCGG (HIS4, HaeIII-1, 1228)

Mapping DSB sites by genomic sequencing, primer extension and Southern analysis: The protocol that we used is based on that of LIU et al. (1995). The $3^{\prime}$ termini of the DSBs were mapped directly by Southern analysis of restriction fragments of meiotic DNA separated by polyacrylamide gels; the mobility of bands was detected by hybridization to strandspecific probes. Ten micrograms of yeast DNA (meiotic or mitotic) were cut with $B s t \mathrm{UI}$ (to map the termini on the $B I K I$ side of the DSB, called DSB(L)) or HaeIII (to map the termini on the HIS4 side of the DSB, called DSB(R)).

For mapping $5^{\prime}$ termini of DSBs, eight rounds of primer extension were performed using Taq DNA polymerase. Two micrograms of meiotic yeast DNA (untreated with restriction enzymes) were used as templates for primer extension. The $20 \mu \mathrm{l}$ of reactions contained $2 \mu \mathrm{l}$ of $1.25 \mathrm{mM}$ dNTP, $2 \mu \mathrm{l}$ of $10 \times$ Taq DNA polymerase buffer [100 mM Tris ( $\mathrm{pH} 8.3$ ), 500 $\mathrm{mM} \mathrm{KCl}, 0.01 \%$ glycerol, $20 \mathrm{mM} \mathrm{MgCl}_{2}$ ], $0.5 \mu 1$ of $40 \mu \mathrm{M}$ primer (primer 10083 for DSB(L), 10193 for $\operatorname{DSB}(\mathrm{R})$ ), $0.5 \mu \mathrm{l}$ of Taq DNA polymerase ( 5 units $/ \mu \mathrm{l}$ ) and $15 \mu \mathrm{l}$ of a DNA solution; in some experiments, we used primers that were one base displaced from the BstUI or HaeIII sites, 10918 (DSB(L)) and $10929(\mathrm{DSB}(\mathrm{R}))$. Samples were heated to $94^{\circ}$ for $1.5 \mathrm{~min}$, and then eight cycles of primer extension $\left(94^{\circ}\right.$ for $1.5 \mathrm{~min}$, $58^{\circ}$ for $2 \mathrm{~min}$, and $72^{\circ}$ for $2 \mathrm{~min}$ ) were performed. After the last cycle, the samples were incubated at $72^{\circ}$ for $7 \mathrm{~min}$.

The DNA samples used for mapping the $3^{\prime}$ and $5^{\prime}$ termini were extracted with phenol, ethanol precipitated, and dissolved in $10 \mu \mathrm{l}$ of $\mathrm{H}_{2} \mathrm{O}\left(65^{\circ}\right.$ incubation for $\left.1 \mathrm{hr}\right)$. To control for the lane-to-lane variation in electrophoretic mobility, DNA samples for mapping were mixed with a size standard. For $\mathrm{DSB}(\mathrm{L})$ mapping, the size standard was a PruII-BstUI fragment (BIK1 region) derived from pMW50; for DSB(R) mapping, the size standard was a PCR product (HIS4 region) obtained by amplifying pMW50 DNA with primers 9905 and 10193 using Pfu DNA polymerase (Stratagene). Pfu DNA polymerase is $\sim 12$-fold more accurate than Taq DNA polymerase (AUsubel et al. 1993).

To map DSBs at single-base pair resolution, it is necessary to use DNA sequence ladders in adjacent lanes that are derived from the same region of the genome. These ladders were prepared using $0.6 \mu \mathrm{g}$ of plasmid pMW50 and primers $10083(\mathrm{DSB}(\mathrm{L}))$ or $10193(\mathrm{DSB}(\mathrm{R}))$ and the thermal cycle DNA sequencing kit ( $f m o l$ DNA sequencing system, Promega). The DNA was divided among four individual sequencing reactions, each containing a volume of $6 \mu \mathrm{l}$. The conditions recommended by the manufacturer were used in the reactions. About $0.3 \mu$ l of each sequencing reaction was used for each gel lane.

Before DNA samples were loaded for gel electrophoresis, the DNA was denatured by boiling for $10 \mathrm{~min}$. The samples were run on $6 \%$ polyacrylamide gels $(0.4 \mathrm{~mm}$ thick) containing $7 \mathrm{M}$ urea at $1500 \mathrm{~V}$ for $4 \mathrm{hr}$. DNA was then transferred to Hybond $\mathrm{N}+$ membranes with a Hoeffer Gene Sweep transfer apparatus. The DNA was fixed to the membrane by incubation at $80^{\circ}$ for $30 \mathrm{~min}$ followed by crosslinking of the DNA by using ultraviolet irradiation $(300 \mathrm{~nm}$ ) for $4 \mathrm{~min}$ (dose of $\sim 1700 \mathrm{~J} / \mathrm{m}^{2}$ ).

Strand-specific probes for polyacrylamide sequencing gels were made by multiple-cycle primer extension (STURzL et al. 1990), using substrates generated by PCR. The substrate for detecting DSB(L) was made using the plasmid pFX2b as a template and primers 7492 and 8172 in a PCR; the same plasmid and the primers 9905 and 1233 were used to prepare the substrate for detecting $\operatorname{DSB}(\mathbf{R})$. Both PCR products were gel purified. To prepare the single-stranded probe, we set up $25 \mu \mathrm{l}$ of reactions containing $2.5 \mu \mathrm{l}$ of $10 \times$ Taq DNA polymerase buffer (same as above), $0.5 \mu \mathrm{l}$ of $250 \mu \mathrm{M}$ dCTP, dGTP 
and dTTP, $0.5 \mu \mathrm{l}$ of Taq DNA polymerase ( 5 units $/ \mu \mathrm{l}$ ), $1 \mu \mathrm{l}$ of $1 \mu \mathrm{M}$ primer $(8172$ for the DSB(L) probe, 9905 for the $\mathrm{DSB}(\mathrm{R})$ probe), $0.5 \mu \mathrm{l}(20 \mathrm{ng})$ of the double-stranded DNA template, and $19 \mu \mathrm{l}$ of $\alpha-{ }^{32} \mathrm{P}-\mathrm{dATP}(3000 \mathrm{Ci} / \mathrm{mmol}$, Amersham). Twenty-five cycles of primer extension ( $94^{\circ}$ for $1 \mathrm{~min}$, $55^{\circ}$ for $1 \mathrm{~min}$ and $72^{\circ}$ for $2 \mathrm{~min}$ ) were performed. The probe was purified with a Sephadex G50 column. We used the hybridization protocols recommended for Hybond-N+ by the manufacturer (Amersham).

As described above, the lanes containing the DSB samples also contained size standards. To map the DSB sites, we aligned the DNA fragments representing the size standards to the appropriate sequence on the DNA sequencing ladders. The fragments representing the DSB sites could then be aligned to the sequencing ladder at single base pair resolution. Excellent agreement was found for alignments estabilished independently by two different people.

Addition of an untemplated nucleotide by Taq DNA polymerase: Taq DNA polymerase adds an untemplated base during PCR reactions (HEMSLEY et al. 1989). To determine whether this reaction occurred under our experimental conditions, we did primer extensions with PunlI-treated pMW50 DNA $(0.01 \mu \mathrm{g}$ in a $20 \mu \mathrm{l}$ reaction mixture) performed under the same conditions described above; the primer 10083 was used and eight cycles of primer extension were done. The primer 10083 begins at the BstUI cleavage site. Thus, if no untemplated terminal base is added, the primer extension product should be identical in size to the PvuII-BstUI fragment derived from pMW50. By analyzing the product in a DNA sequencing gel, however, we found that the primer extension product was one base longer than the PvuII-BstUI fragment (data not shown), indicating the addition of an untemplated base.

Analysis of DNA termini using exonuclease III: As shown in Table 1, DNA termini with blunt ends, 5' overhangs or 3' overhangs less than four bases are degraded by exonuclease III by a 3' to 5' activity (BRUTLAG and KORNBERG 1972; HENIKOFF 1984). If 5 ' overhangs are "filled in" by DNA polymerase using $\alpha$-phosphorothioate dNTPs ( $\alpha$ S-dNTPs), then the modified ends are resistant to exonuclease III (PUTNEy et al. 1981). Both modified and unmodified termini were examined in our experiments.

Yeast meiotic DNA $(84 \mu \mathrm{g})$ were cut with HaelI and Sad for DSB detection; both Haell and Sad generate four base 3' overhangs (SAMBROOK et al. 1989). Four micrograms of pBR322 were cut with AvaI, BamHI and RsaI as controls for $5^{\prime}$ overhang termini (AvaI and BamHI fragments) and blunt termini (RsaI fragment) (SAMBROOK et al. 1989). These treated DNAs were mixed, extracted with phenol, precipitated with ethanol and dissolved into $80 \mu \mathrm{l}$ of TE (10 mM Tris, $1 \mathrm{mM}$ EDTA pH 8.0). Forty microliters of the DNA solution was removed for treatment with DNA polymerase and $\alpha S-d N T P s$. The remaining $40 \mu \mathrm{l}$ of DNA were analyzed without modification. To modify the termini, we added to the $40 \mu \mathrm{l}$ of DNA, $10 \mu \mathrm{l}$ of $10 \times$ Klenow buffer (NEB), $10 \mu \mathrm{l}$ of $\alpha \mathrm{S}-\mathrm{dNTPs}(0.4 \mathrm{mM}$, Promega), $1 \mu \mathrm{l}$ of dithiothreitol $(0.1 M), 1 \mu \mathrm{l}$ of Klenow/exo ${ }^{-}$ DNA polymerase ( 5 units/ $\mu \mathrm{l}, \mathrm{NEB}$ ), and $38 \mu \mathrm{l}$ of $\mathrm{H}_{2} \mathrm{O}$. The solution was incubated at $37^{\circ}$ for $10 \mathrm{~min}$, and DNA was then extracted with phenol and precipitated with ethanol. The modified DNA was dissolved in $40 \mu \mathrm{l}$ of TE.

From the $40-\mu \mathrm{l}$ aliquots of the modified and unmodified DNA samples, we used $32 \mu \mathrm{l}$ of DNA for exonuclease III treatment and $8 \mu \mathrm{l}$ as an untreated control. For the exonuclease III reaction, we mixed the $32-\mu$ l DNA solutions with $5 \mu$ l of $10 \times$ exonuclease III buffer (NEB), $4 \mu \mathrm{l}$ of exonuclease III (100 units/ $\mu \mathrm{l}, \mathrm{NEB}$ ) and $9 \mu \mathrm{l}$ of $\mathrm{H}_{2} \mathrm{O}$. The solutions were incubated at $30^{\circ}$. Seventeen-microliter samples were removed after $30 \mathrm{sec}, 1 \mathrm{~min}$ and $3 \mathrm{~min}$ and placed on dry ice. Exonuclease III was inactivated by incubating the samples at $70^{\circ}$
DSB(L)

DSB(R)

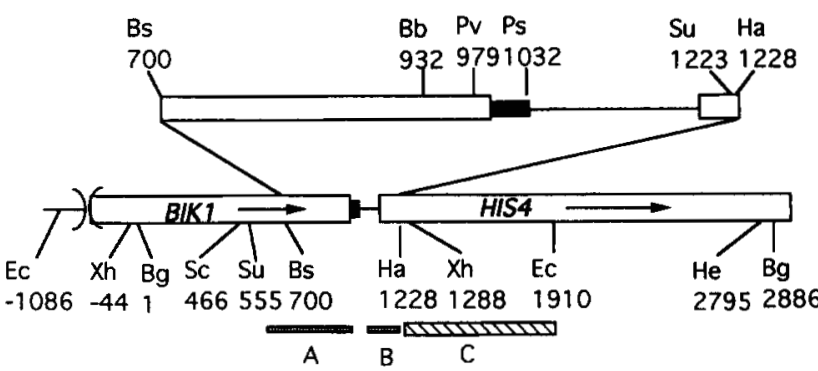

FIGURE 1.-Restriction map of the chromosomal region flanking the HIS4 hotspot associated with a telomeric insertion. The directions of transcription are shown by arrows, and the labeled rectangles represent the $B I K 1$ and $H I S 4$ coding sequences. $\mathrm{DSB}(\mathrm{L})$ and $\mathrm{DSB}(\mathrm{R})$ indicate the regions to the left and right, respectively, of the hotspot-associated DSBs. Numbers under the restriction sites represent the distances from the BgII site in BIK1. $\square$, the telomeric insertion. The stippled rectangle marked A shows the location of the singlestranded hybridization probe (595-960) used to analyze $\mathrm{DSB}(\mathrm{L})$ and the stippled rectangle marked $\mathrm{B}$ indicates the location of the single-stranded probe (1049-1223) used to analyze $\mathrm{DSB}(\mathrm{R})$; the cross-hatched rectangle (marked $\mathrm{C}$ ) represents the sequences derived from $\mathrm{pDN} 42$ used as a probe in the Southern analyses shown in Figure 2. Not all restriction sites for the indicated enzymes are shown. Ec, EcoRI; Xh, XhoI; Bg, BglI; Sc, Sad; Su, Sau3AI; Bs, BstUI; Bb, BbsI; Pv, PvuII; Ps, Pstl; Ha, HaelII; He, HaelI.

for $20 \mathrm{~min}$. For the 8- $\mu 1$ DNA samples that were not treated with exonuclease III, we added $1.7 \mu \mathrm{l}$ of $10 \times$ exonuclease III buffer and $7 \mu \mathrm{l}$ of water to generate a $17-\mu \mathrm{l}$ sample size.

The end products of exonuclease III treatment of appropriate substrates are single-stranded DNA molecules. To complete degradation of the DNA, we digested the exonuclease III-treated samples with mung bean nuclease, an enzyme that degrades single-stranded DNA (SAMBROOK et al. 1989). Each $30-\mu \mathrm{l}$ reaction contained $17 \mu \mathrm{l}$ of DNA, $3 \mu \mathrm{l}$ of $10 \mathrm{mM} \mathrm{ZnSO}_{4}$, $1.3 \mu \mathrm{l}$ of $10 \times$ exonuclease III buffer, $2 \mu \mathrm{l}$ of mung bean nuclease ( 10 units $/ \mu \mathrm{l}, \mathrm{NEB}$ ) and $6.7 \mu \mathrm{l}$ of $\mathrm{H}_{2} \mathrm{O}$. The samples were incubated at $30^{\circ}$ for $30 \mathrm{~min}$ and then examined by Southern analysis. The HIS4-specific hybridization probe was an EcoRI-XhoI fragment derived from pDN42.

Mapping DSB sites by anchor-PCR: For each experiment, $3 \mu \mathrm{g}$ of yeast DNA were treated with XhoI, extracted with phenol/chloroform, and precipitated with ethanol. The DNA was resuspended in $42 \mu \mathrm{l}$ of $\mathrm{H}_{2} \mathrm{O}$ and denatured at $100^{\circ}$ for $10 \mathrm{~min}$. Twenty-one microliters of the denatured DNA was used for the terminal deoxynucleotide transferase (TdT) "tailing" reaction. We then added $6 \mu \mathrm{l}$ of $5 \times$ TdT buffer (USB), $2 \mu \mathrm{l}$ of $1 \mathrm{mM}$ dGTP, and $1 \mu \mathrm{l}$ of TdT (USB, 17 units/ $\mu 1)$. The reaction was incubated at $37^{\circ}$ for $30 \mathrm{~min}$ then diluted with $\mathrm{H}_{2} \mathrm{O}$ to $100 \mu \mathrm{l}$. These conditions add a single-stranded poly dG tail of $\sim 20$ bases to the 3 ' ends of the substrate DNA, and this modified DNA was used as a substrate for PCR (Bollum 1974).

The primers used to examine $\mathrm{DSB}(\mathrm{L})$ were 7492 and the poly dC primer 7278. DSB(R) was studied using 7680 and 7278. Each $50-\mu \mathrm{l}$ reaction had $5 \mu \mathrm{l}$ of the substrate DNA (described above), $8 \mu \mathrm{l}$ of dNTP $\mathrm{mix}$ (1.25 mM each of dCTP, dGTP, dATP and dTTP), $1.2 \mu \mathrm{l}$ of primer 7492 or 7680 (40 $\mu \mathrm{M}$ concentration of oligonucleotide), $1.2 \mu \mathrm{l}$ of the 7278 primer ( $40 \mu \mathrm{M}$ stock), $5 \mu \mathrm{l}$ of $10 \times$ Taq DNA polymerase buffer (described above), $28.5 \mu \mathrm{l}$ of $\mathrm{H}_{2} \mathrm{O}$, and $1 \mu \mathrm{l}$ of Taq DNA polymerase (5 units/ $\mu$ l, Perkin-Elmer). The PCR machine (Perkin-Elmer Cetus) was run for 45 cycles with the following 


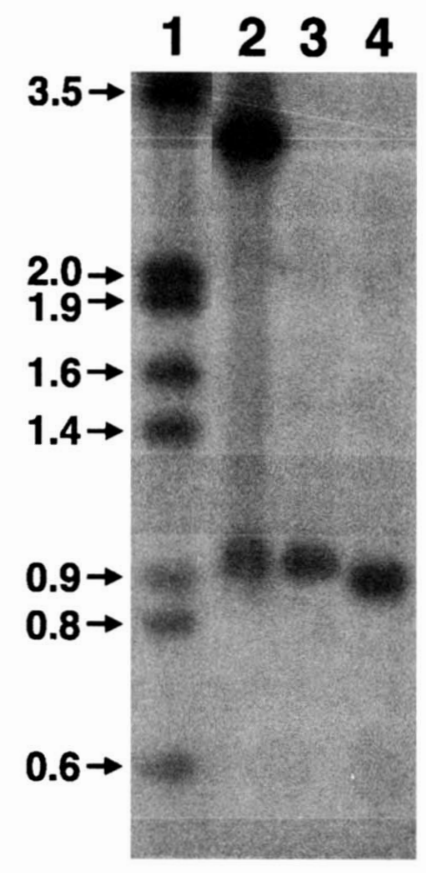

FIGURE 2.-Southern analysis of the hotspot-associated DSB at HIS4. A mixture of yeast DNA derived from pDN42 (position of probe shown in Figure 1) and lambda DNA was used as a hybridization probe. Lane 1, HindIII/EcoRI-treated lambda DNA; lane 2, DNA isolated from meiotic cells of FX4 and treated with EcoRI. The top band represents the intact EcoRI fragment and the bottom band represents the DSBgenerated fragment. Lane 3, DNA isolated from mitotic cells treated with EcoRI and $B b s \mathrm{~s}$; lane 4, DNA isolated from mitotic cells treated with EcoRI and PvuII.

temperatures and times for each cycle: $94^{\circ}$ for $1 \mathrm{~min}, 65^{\circ}$ for $2 \mathrm{~min}, 72^{\circ}$ for $3 \mathrm{~min}$. After the last cycle, the sample was incubated at $72^{\circ}$ for $7 \mathrm{~min}$.

The PCR products were checked using a $1.2 \%$ low-meltingtemperature agarose gel. The PCR products representing the DSBs were cut out and purified using the protocols provided with the Promega Wizard PCR. To further confirm that the PCR products were from the HIS4 DSBs rather then a nonspecific product, this PCR product was checked by Southern analysis using pFX2b as a probe or by a nested PCR reaction using primer $7981(\mathrm{DSB}(\mathrm{L}))$ or $7982(\mathrm{DSB}(\mathrm{R}))$ and primer 7278. The PCR product was cloned with the TA cloning kit (Invitrogen). The resulting plasmids were sequenced by standard methods.

\section{RESULTS}

In previous studies (WHITE et al. 1993; FAN et al. 1995), we found that an insertion of telomeric sequences greatly stimulated the frequency of meiotic recombination and DSBs at the HIS4 locus. Below, we describe the mapping of these breaks and an analysis of some features of the broken ends.

Mapping the position of DSBs by agarose gel electrophoresis: The diploid strain FX4 is homozygous for the rad50S mutation and for an insertion of telomeric sequences upstream of HIS4. In meiosis, a DSB is observed in this strain near the site of the telomere insertion (FAN et al. 1995). To refine the mapping of the position of the DSB, we used restriction enzymes that

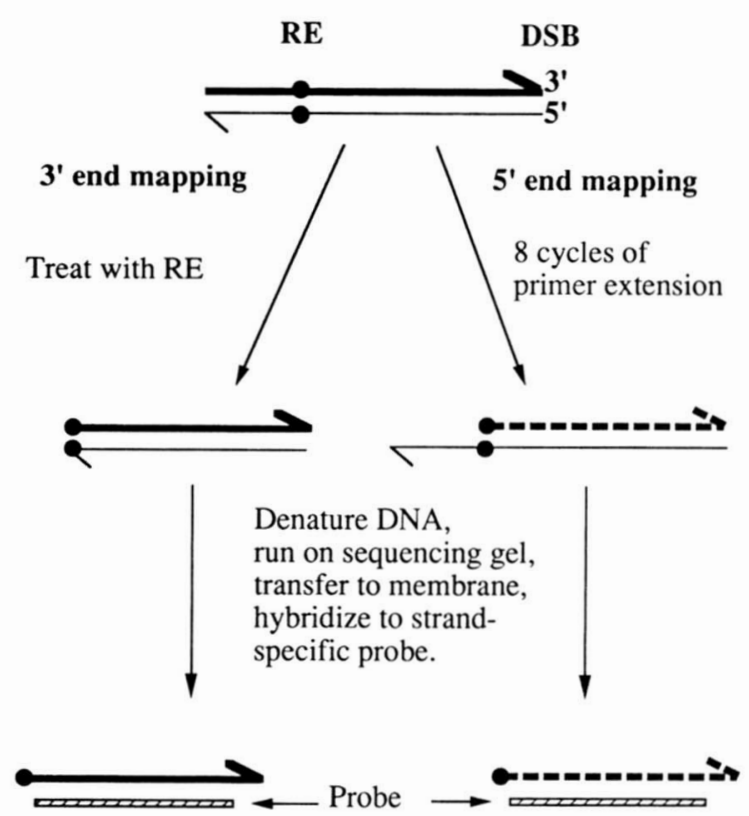

FIGURE 3.-Mapping 3 ' and 5' DSB-generated termini. The mapping of sequences on only one side of the break is depicted. The $3^{\prime}$ ends (thick lines) were mapped by treating the DNA with a restriction enzyme (RE) that cuts at a site close (within 200-300 bp) to the DSB site (BstUI for DSB(L) and HaeIII for $\operatorname{DSB}(\mathrm{R}))$. The resulting DNA was denatured, run on DNA sequencing gels, transferred to a membrane, and hybridized to a strand-specific probe. The $5^{\prime}$ ends (thin lines) were mapped by denaturing unrestricted DNA, and performing eight cycles of primer extensions using a primer located at the same restriction site used in the analysis of $3^{\prime}$ ends. This primer hybridized to the thin strand and was extended to the $5^{\prime}$ end; the resulting product is shown with a thick dashed line. The DNA molecules resulting from these manipultations were denatured and examined as described for the $3^{\prime}$ termini.

generated restriction fragments shorter than those used in the previous study. As shown in Figure 1, the telomeric insertion is bracketed by PvuII and PstI sites, and there is a BbsI site in BIK1 $\sim 50$ bp from the PouII site. When DNA was isolated from meiotic cells, treated with EcoRI, and examined by Southern analysis (using a probe derived from the HIS4, Figure 1), a DSB fragment of $\sim 1 \mathrm{~kb}$ was observed. This fragment comigrated with an EcoRI-BbsI fragment derived from mitotic cells but was distinctly larger than an EcoRI-PvuII fragment (Figure 2). Thus, the DSB cleavages occur on the BIK1 side of the telomere insertion. In addition, since the band representing the DSB is only slightly wider than the bands representing restriction fragments, the DSB sites are restricted to a small chromosomal interval.

Mapping DSB sites by primer extension and Southern analysis: The method that we used to map DSB sites to single-base pair resolution (Figure 3) is based on methods developed for genomic sequencing (CHURCH and Gilbert 1984; Huibregste and Engelke 1991), as modified by LIU et al. (1995). A DSB within the HIS4 hotspot produces two DNA fragments with two DSBgenerated termini. The terminus of the fragment with $B I K 1$ sequences will be called $\mathrm{DSB}(\mathrm{L})$ and the terminus 
A.

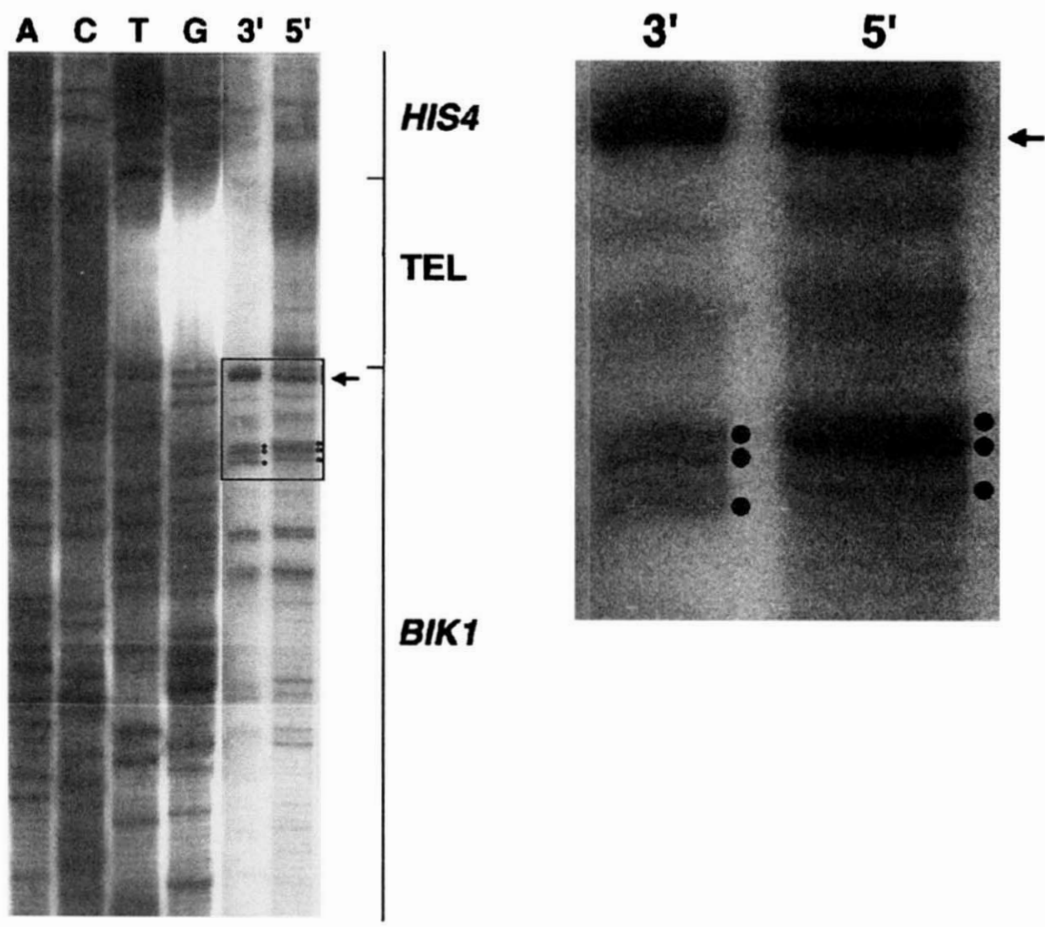

Figure 4.-Mapping the $3^{\prime}$ and $5^{\prime}$ termini of DSB(L). (A) As outlined in Figure 3, the 3' ends were examined by direct Southern analysis and the $5^{\prime}$ ends mapped by primer extension. For the $3^{\prime}$ analysis, meiotic DNA was treated with $B s t$ UI. The oligonucleotide (10083) used for the primer extensions began at the $B s t \mathrm{UI}$ site. The DNA sequencing ladder was also prepared using the 10083 primer. The arrow indicates the position of a PruII-BstUI fragment (derived from pMW50) added to the $5^{\prime}$ and 3' samples as a size standard. A strand-specific probe derived from the $B I K 1$ region (Figure 1) was used to detect the positions of the breaks. The outlined region of the gel indicates the area shown at higher magnification in Figure 4B. Dots indicate three prominent DSB bands. (B) Magnified region of gel lanes shown in Figure $4 \mathrm{~A}$. The bands representing the control PuulI-Bst UI fragment are in direct alignment, whereas the bands representing the $3^{\prime}$ DSBs are one base pair shorter than those representing the $5^{\prime}$ DSBs. of the fragment with HIS4 sequences will be called $\operatorname{DSB}(\mathrm{R})$. Both ends were mapped by similar procedures, and we describe the mapping of DSB(L) first.

DNA was isolated from strain FX4 after the cells had been incubated in sporulation medium for $24 \mathrm{hr}$. To measure the position of breaks at the $3^{\prime}$ end of DSB(L), we treated the meiotic DNA with $B s t \mathrm{UI}$, separated the fragments on a polyacrylamide DNA sequencing gel, and hybridized the separated fragments with a strandspecific probe. We included a DNA sequencing ladder from this region of the genome on the same gel (Figure $4 \mathrm{~A})$. Since this sequencing ladder was obtained using a primer that started at the BstUI site, it is aligned with the DSB ends. It is clear from Figure 4A that there are multiple 3 ' ends. Although there are faint bands at many positions in the gel lane, the strongest bands are mostly distributed within a 50-bp region. There are no strong breaks in the telomeric sequences. No DSBs were detectable in DNA derived from mitotic cells by standard Southern procedures (FAN et al. 1995) or by Southern analysis using DNA sequencing gels (data not shown).

The 5' ends of DSB(L) were mapped by primer extension. We used primer extension, rather than directly examining the position of the DSBs using a different strand-specific probe, for two reasons. First, the primer extension analysis allowed us to compare DNA strands that had the same sequence and, therefore, the same molecular weight. The position of breaks in the two strands could be established using the same DNA sequencing ladder and the same size standard. Second, other researchers observed a protein attached to the $5^{\prime}$ end of the DSB in yeast (DE MASSY et al. 1995; KeENEY and KLECKNER 1995; LIU et al. 1995). This attached protein would be expected to affect the migration of the $5^{\prime}$ strand. The primer extension method allows one to map the position of the $5^{\prime}$ end without this complication. Using an oligonucleotide primer with sequences that begin at the BstUI site, we performed eight rounds of primer extensions (unidirectional PCR, details in MATERIALS AND METHODS). The resulting products were analyzed as described above for the $3^{\prime}$ ends and showed a similar pattern of bands (Figure 4A). To compare relative mobilities of DNA representing the $3^{\prime}$ and $5^{\prime}$ ends, we included the same size standard in both lanes, the BstUI-PyuII restriction fragment shown in Figure 1. The alignment of the $5^{\prime}$ and $3^{\prime}$ ends of DSB(L) indicated that the $5^{\prime}$ ends were displaced by one base pair (Figure 4B). Since Taq DNA polymerase adds an extra terminal base during PCR amplification (HEMSLEY et al. 1989), the simplest explanation of this result is that the $5^{\prime}$ and $3^{\prime}$ cleavages occur at the same position in the DNA molecule, indicating that ends generating by DSBs are blunt. We confirmed this conclusion by reanalyzing the $5^{\prime}$ ends using a DNA primer that was recessed one base from Bst $U$ I site (Figure 5 ). When the DNA samples representing the $3^{\prime}$ ends and the primer extension product representing the $5^{\prime}$ ends were mixed, it was clear that the $5^{\prime}$ and $3^{\prime}$ bands comigrated. When primer extension experiments were done on DNA isolated from mitotic cells, a few faint bands were seen, but the number and intensity of these bands varied in different primer extension reactions (data not shown).

The map positions of the DSB(L) ends are summarized in Figure 6. Most of the DSB(L) ends appear blunt, although there are some bands that appear in the 


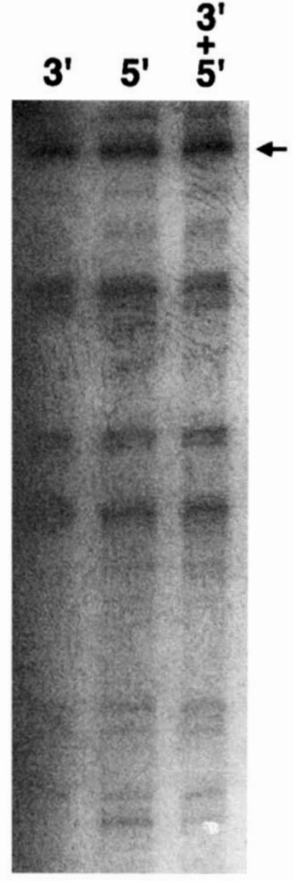

FIGURE 5.-Mapping of DSB(L) using a different primer for primer extension. The $3^{\prime}$ termini were mapped as described in Figure 4 . The $5^{\prime}$ termini were analyzed using a primer (10918) one base displaced from the BstUI site. Thus, since primer extension with Taq DNA polymerase results in the addition of an untemplated base with this protocol (HEMSLEY et al. 1989; see MATERIALS AND METHODS), the 5' and 3' strands should comigrate if the DSB results in a blunt end. Since the lane containing a mixture of the $5^{\prime}$ and $3^{\prime}$ strands has the same pattern of bands as the lanes with the individual strands, the DSB-generated termini are blunt.

$5^{\prime}$ mapping that are not represented in the $3^{\prime}$ mapping (Figure 4); such bands could represent a low level of sequence-specific nicking or could reflect premature termination during the primer extension reaction. To confirm the conclusion that the DSB(L) ends were blunt, we also mapped the DSB $(\mathrm{R})$ ends by similar procedures (Figure 7). The $3^{\prime}$ ends were mapped by treating meiotic DNA with HaeIII, separating the cleavage products with DNA sequencing gels and hybridizing to a strand-specific probe. The $5^{\prime}$ ends were mapped using a primer that was displaced by one base from the HaelII site. Relative to the DNA sequencing standard, the 3' ends mapped at the positions expected for a blunt end cleavage. Although most of the $5^{\prime}$ and $3^{\prime}$ ends derived from $\operatorname{DSB}(\mathrm{R})$ were at the same positions, there were fewer bands observed for the $5^{\prime}$ ends, and the relative band intensities were different for the $5^{\prime}$ and $3^{\prime}$ ends. Although some of these discrepancies may represent a low level of site-specific strand nicks, it is more likely that additional bands or differences in band intensities reflect artifacts of the primer extension procedure. In summary, most of the ends generated by DSBs at the HIS4 hotspot appear to be blunt, in agreement with the results of DE MASSY et al. (1995) at the CYS3 hotspot.

Since the methods described above involve denaturing the DNA, some of the observed break positions

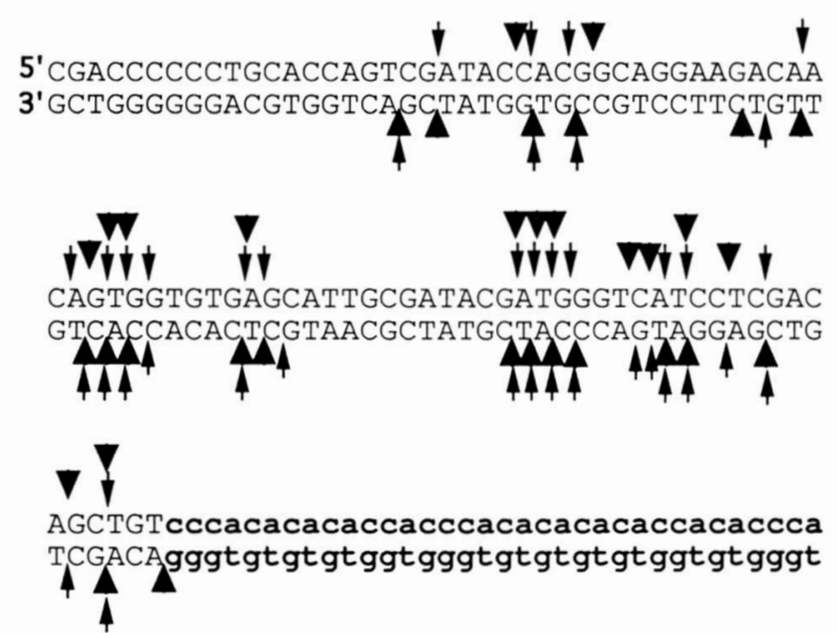

caccacaccaacccactCTGCAGTCGAGGTATGAACAGTA gtggtgtggttgggtgAGACGTCAGCTCCATACTTGTCAT

Figure 6.-Patterns of break sites determined by direct Southern analysis and primer extension. This figure summarizes the mapping of $\mathrm{DSB}(\mathrm{L})$ and $\mathrm{DSB}(\mathrm{R})$ that was performed by analyzing gels such as those shown in Figures 4, 5 and 7; more than five independent gels for both $\mathrm{DSB}(\mathrm{L})$ and $\operatorname{DSB}(\mathrm{R})$ were used to generate these data. The slender and thick arrows represent mapping of $3^{\prime}$ and $5^{\prime}$ ends, respectively. Arrows above and below the sequence show cleavage sites on the upper and lower strands, respectively. Thus, the mapping of $\operatorname{DSB}(\mathrm{L})$ is represented by thin arrows on the top strand and thick arrows on the bottom strand, and the mapping of $\operatorname{DSB}(\mathrm{R})$ is shown by thick arrows on the top strand and thin arrows on the bottom strand. The telomeric repeats are shown in lowercase letters, and sequences to the left of the telomeric repeats are BIKl sequences.

could reflect nicks rather than DSBs. Consequently, we did two-dimensional agarose gel electrophoresis (neutral gel electrophoresis followed by alkaline gel electrophoresis) to look for site-specific nicks. No specific nicks were detected in this analysis (data not shown), in agreement with similar studies done by the three other groups of workers mapping DSBs at recombination hotspots (DE MAssy et al. 1995; LiU et al. 1995; XU and KLECKNER 1995).

Although the methods used in our study were not designed to detect proteins bound to the $5^{\prime}$ end of DSBgenerate termini, several other groups (DE MASSY et al. 1995; KEENEY and KLECKNER 1995; LiU et al. 1995) have reported such proteins. If this protein prevented complete primer extension, the observation that the $5^{\prime}$ and $3^{\prime}$ ends from $\operatorname{DSB}(\mathrm{L})$ and $\operatorname{DSB}(\mathrm{R})$ have the same electrophoretic mobility could be misleading. For example, if the DSB ends had 5 ' overhangs of $2 \mathrm{bp}$, but the bound protein resulted in a primer extension product that was 2 bp short of the true end, then the termini would look blunt. Under this circumstance, however, the breakpoints mapped for DSB(L) would be displaced from those mapped for DSB(R) by $4 \mathrm{bp}$. Thus, the finding that most of the breakpoints derived from $\operatorname{DSB}(\mathrm{L})$ are the same as those derived from $\operatorname{DSB}(\mathrm{R})$ 

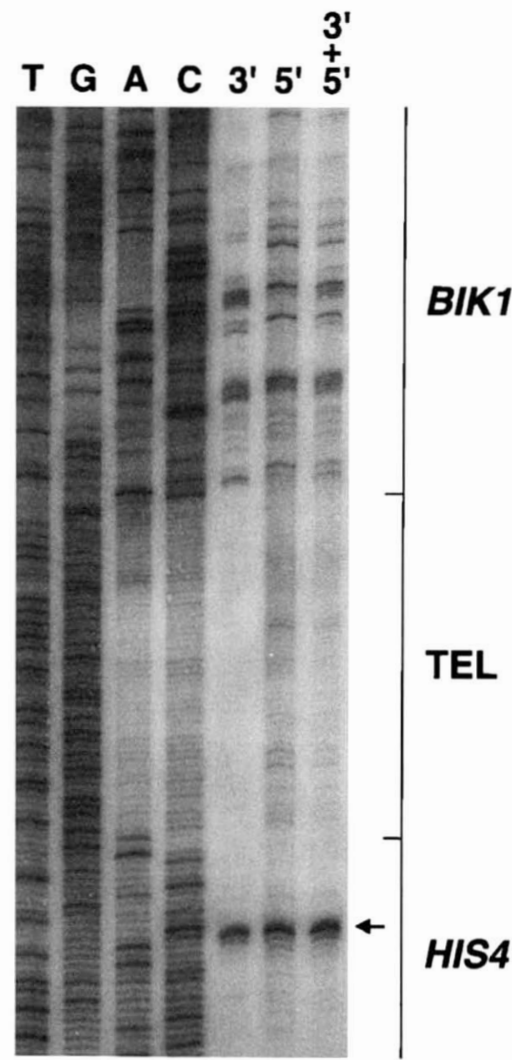

Figure 7.-Mapping the $3^{\prime}$ and $5^{\prime}$ termini of DSB(R). The 3' lane contains meiotic DNA treated with HaelII. The 5' lane contains the products of a reaction in which meiotic DNA was used as a substrate for primer extension with the oligonucleotide 10929 (one base recessed from the HaelII site). The DNA sequencing ladder was prepared using a primer (10193) at the HaeIII site. The arrow shows the position of migration of a size standard mixed with the $5^{\prime}$ and $3^{\prime}$ DNA samples. As described in MATERIALS AND METHODS, the 181-bp size standard was generated by PCR amplification of pMW50, using primers 10193 (which align at the HaeIII site) and 9905; this fragment has DNA sequences identical to those in the DNA sequencing ladder. The rightmost lane contains a mixture of $5^{\prime}$ and $3^{\prime}$ DNA samples. After electrophoresis, the DNA fragments were transferred to Hybond-N+ and hybridized to a strand-specific probe (described in MATERIALS AND METHODS) containing HIS4 sequences.

supports the conclusion that the DSB-generated ends are blunt. This conclusion is also reinforced by the exonuclease digestion experiments described below.

Analysis of DSB-produced DNA ends with exonuclease III: Exonuclease III catalyzes the stepwise release of mononucleotides from the $3^{\prime} \mathrm{OH}$ ends of the following DNA substrates (BRUTLAG and KORNBERG 1972; SAMBROOK et al. 1989): ends with $5^{\prime}$ overhangs, blunt ends, ends with 1-3-base $3^{\prime}$ overhangs, and nicked double-stranded DNA molecules. Exonuclease III is unable to degrade linear DNA with a $3^{\prime}$ overhang that is greater than or equal to four bases (HENIKOFF 1984) or a DNA molecule in which a $5^{\prime}$ overhang has been filled in with $\alpha$-phosphorothioate dNTPs ( $\alpha \mathrm{S}$ dNTP) (PUTNEY et al. 1981).

To analyze the nature of the termini produced by
TABLE 1

Diagnosis of DNA termini by treatment with exonuclease III

\begin{tabular}{lcc}
\hline & \multicolumn{2}{c}{$\begin{array}{c}\text { Sensitivity to exonuclease III } \\
\text { treatment }{ }^{a}\end{array}$} \\
\cline { 2 - 3 } & $\begin{array}{c}\text { Unmodified } \\
\text { DNA ends }\end{array}$ & $\begin{array}{c}\text { Modified } \\
\text { DNA ends }\end{array}$ \\
\hline \multicolumn{1}{c}{ Type of DNA ends } & $\mathrm{R}$ & $\mathrm{R}$ \\
$3^{\prime}$ overhang ( $\geq 4$ bases $)$ & $\mathrm{S}$ & $\mathrm{R}$ \\
$5^{\prime}$ overhang & $\mathrm{S}$ & $\mathrm{S}$ \\
$\begin{array}{l}\text { Blunt or 3' overhang } \\
(<4 \text { bases })\end{array}$ & $\mathrm{S}$ & $\mathrm{S}$ \\
\hline
\end{tabular}

${ }^{a} \mathrm{R}$ indicates resistance and $\mathrm{S}$ indicates sensitivity to exonuclease III digestion.

${ }^{b}$ The modification is treatment of the DNA with the Klenow fragment of DNA polymerase and $\alpha \mathrm{S}$-dNTPs. For DNA termini with a $5^{\prime}$ overhang, this treatment will result in bluntended termini that are resistant to exonuclease III digestion.

the meiosis-specific DSB, we examined the sensitivity of these ends to exonuclease III, before and after treatment of the ends with DNA polymerase and $\alpha$ S-dNTPs. We monitored the sensitivity of the ends to exonuclease III by Southern analysis. A summary of the results expected for exonuclease digestion of various types of termini is given in Table 1 . As indicated in this table, termini with a $3^{\prime}$ overhang greater than or equal to four bases in length will be resistant to exonuclease III, with or without treatment of the DNA with DNA polymerase and $\alpha$ S-dNTPs. Both SacI and HaeII cleave DNA to generate termini with four base 3 ' overhangs (SAMBroOK et al. 1989). The HIS4 hotspot region is included in a 2.3-kb SacI-HaeII fragment (Figure 1), and the sites of DSBs are located $\sim 500$ bp from the Sad site and $1.8 \mathrm{~kb}$ from the HaelI site. As shown in Figure $8 \mathrm{~A}$, the 2.3-kb SacI-HaeII fragment without the DSB was resistant to digestion with exonuclease III, as expected. The 1.8-kb band representing the DSB was sensitive to exonuclease III. Since this band should represent fragments with one exonuclease III-resistant HaeII terminus, this result indicates that the end produced by the DSB does not have a $3^{\prime}$ overhang that is four bases or longer (Table 1).

As a control, plasmid pBR322 DNA treated with the enzymes BamHI and AvaI (which result in termini with 4-bp $5^{\prime}$ overhangs), and $R s a \mathrm{I}$ (which results in bluntended termini) was mixed with the yeast DNA samples. The four plasmid DNA fragments visualized by staining of the gel with ethidium bromide (indicated by arrows in Figure 8) represent (from largest to smallest), RsaIRsaI, BamHI-AvaI, AvaI-RsaI and RsaI-RsaI fragments. As expected, all fragments are sensitive to exonuclease III in DNA samples that have not been treated with DNA polymerase and $\alpha$ S-dNTPs.

DNA samples digested with the same restriction enzymes described above were also treated with DNA polymerase (an exonuclease-deficient preparation of the Klenow fragment) and $\alpha$ S-dNTPs. As shown in Figure $8 \mathrm{~B}$, the DNA fragment representing the DSB was still 

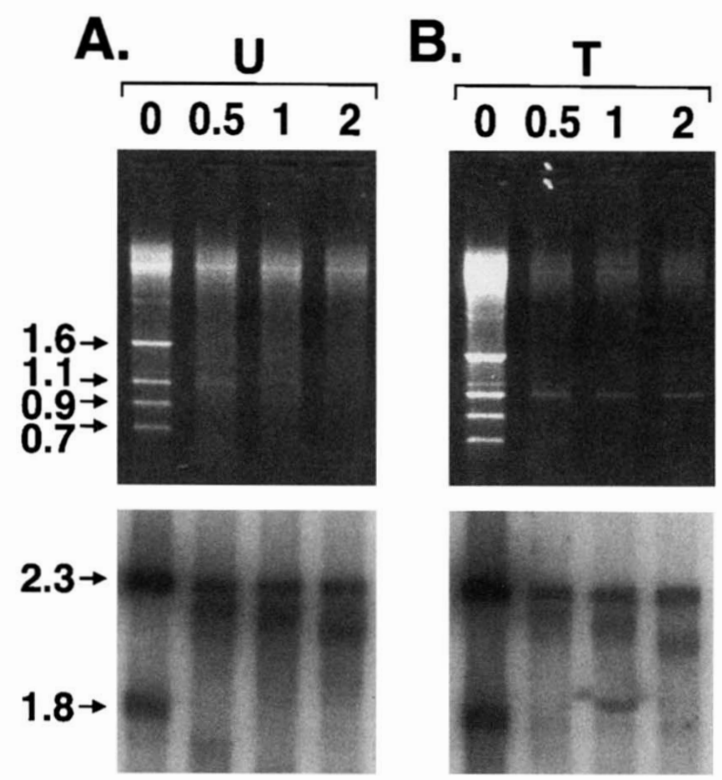

Figure 8.-Analysis of DSB-generated termini using exonuclease III. DNA samples isolated from meiotic cultures of FX4 were digested with SacI and HaeII (enzymes that result in termini with $3^{\prime}$ overhangs of four bases) and were mixed with AvaI/BamHI/RsaI-digested pBR322 DNA; AvaI and BamHI result in termini with four base $5^{\prime}$ overhangs, whereas $R s a$ I results in blunt termini. These samples were either treated with exonuclease III (time of treatment $0,0.5,1$ or 2 min) immediately (A) or were modified by the addition of DNA polymerase and $\alpha \mathrm{S}$-dNTPs before treatment with exonuclease III (B). As detailed in MATERIALS AND METHODS, the DNA samples were then treated with mung bean nuclease and analyzed by gel electrophoresis. The top portions of the figure show the ethidium bromide staining pattern of the gel, and the bottom portions represent Southern analysis of the same gels (after an additional period of electrophoresis) using HIS4-specific fragments derived from pDN42 (Figure 1) as a hybridization probe. The four bands marked by arrows on the top part of A and B represent (from largest to smallest) RsaI-RsaI, BamHI-AvaI, AvaI-RsaI, and RsaI-RsaI fragments of pBR322; the numbers next to the arrows indicate the sizes of the fragments in $\mathrm{kb}$. All fragments were exonuclease IIIsensitive in the untreated (U) samples (A), but the BamHIAvaI fragment became resistant to exonuclease III in the treated (T) samples. As shown in the bottom part of the figure, the 2.3-kb Sact-HaeII fragment (representing meiotic DNA without a DSB) was mostly resistant to exonuclease III treatment, whereas the 1.8 -kb fragment (representing the DSB) was sensitive to exonuclease III with or without modification. The diffuse staining near the top of the gels represents Sacl-HaeII yeast genomic DNA fragments. The lane marked M contained HindIII/EcoRI-treated lambda DNA.

sensitive to exonuclease III following this treatment. The control plasmid DNA BamHI-AvaI fragment was rendered resistant to digestion by exonuclease III, indicating that the DNA polymerase utilized the $\alpha \mathrm{S}$-dNTPs to generate exonuclease III-resistant termini. The simplest interpretation of this result is that the terminus caused by the DSB is blunt or has a 3 ' overhang of less than four bases. These results also argue that the $3^{\prime}$ end of the DSB is not covalently attached to a protein since such an attachment would be expected to make the termini resistant to exonuclease III.
Several other points should be discussed. First, we observed some exonuclease digestion of the 2.3-kb SacIHaelI fragment (Figure 8). A fraction of the SacI or HaeII ends may be sensitive to exonuclease III as a consequence of loss of one or more base pairs of the $3^{\prime}$ overhangs because of a small amount of a contaminating exonuclease. In some preparations of DNA, the exonuclease-sensitive component is only a small fraction of the total (data not shown). Second, a very small fraction of the DSB termini appears resistant to exonuclease III after treatment with DNA polymerase and $\alpha \mathrm{S}$-dNTPs (bottom of Figure 8B). These termini may represent a small fraction of ends that has $5^{\prime}$ overhangs allowing modification to exonuclease III-resistance, or a small amount of DNA polymerase-mediated exchange of the terminal nucleotides. Third, although the plasmid control BamHI-AvaI fragment was made resistant to exonuclease III digestion by treatment with the modified nucleotides, it could be argued that a terminus with a smaller $5^{\prime}$ overhang might be refractory to this modification. We found, however, that $B s t \mathrm{NI}$-generated termini, which have only a single base $5^{\prime}$ overhang, were efficiently modified to resistance to exonuclease III with $\alpha$ S-dNTPs (data not shown). Fourth, we showed that treatment of the plasmid control BamHI-AvaI fragment with DNA polymerase and unmodified nucleotides did not result in the fragment becoming exonuclease III resistant (data not shown). Thus, the resistance does not reflect the activity of a contaminating nuclease of the DNA polymerase that converts $5^{\prime}$ overhangs to $3^{\prime}$ overhangs. In summary, the exonuclease III studies are consistent with our conclusion that most DSB-generated termini at the HIS4 hotspot are blunt.

Mapping meiotic DSBs by PCR: The yeast $S$. cerevisiae has a very high rate of meiotic recombination per $\mathrm{kb}$ relative to most higher eukaryotes, and the rad50S mutation prevents the loss of DNA lesions by subsequent steps of meiotic recombinaton. In organisms without these advantages, the procedures for fine-structure mapping that we and others have used may be difficult to employ. Consequently, we modified the technique of anchor-PCR (FROHMAN et al. 1988) to investigate the placement of DSBs in yeast.

The following procedure was used: (1) The DNA was digested with $\mathrm{XhoI}$ and denatured. (2) The denatured fragments were treated with dGTP and terminal deoxyribonucleotide transferase ( $\mathrm{TdT})$, resulting in addition of a tail of $\sim 20$ dGMP residues to the $3^{\prime}$ ends of all DNA strands (Bollum 1974 and data not shown). (3) PCR amplification was performed using two different sets of primers. One set had one primer with poly $\mathrm{dC}$ sequences (capable of hybridizing to the poly dG tail) and a second containing BIK1 sequences (primer 7492, described in MATERIALS AND METHODS). In DNA derived from mitotic cells, these primers resulted in amplification of a DNA fragment of $\sim 700 \mathrm{bp}$ in DNA (Figure $9 \mathrm{~A}$, lane 2), the expected distance between the primer and the XhoI site in HIS4. In DNA isolated from meiotic 


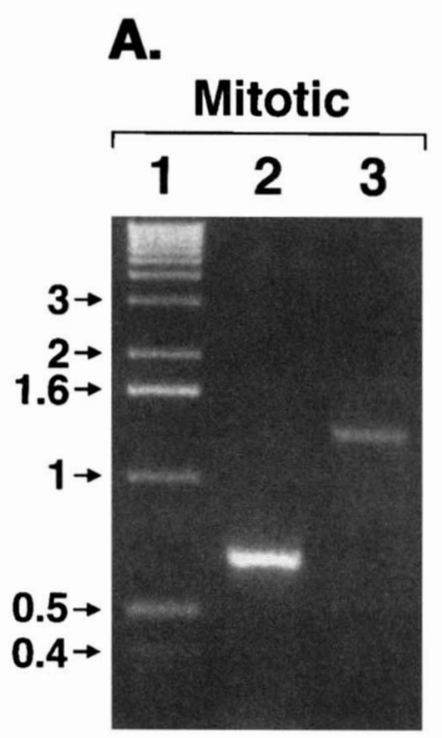

B.

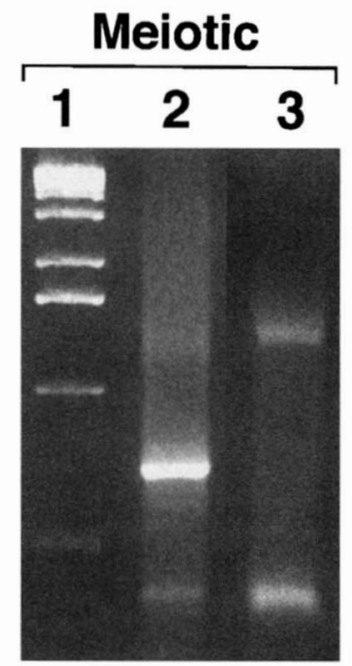

FIGURE 9.-Detection of DSBs by anchor-PCR. DNA was isolated from either mitotic (A) or meiotic (B) cultures of FX4. This DNA was treated with Xhol, terminal transferase and dGTP, and then PCR analysis was performed. To examine $\mathrm{DSB}(\mathrm{L})$ (lanes 2 in $\mathrm{A}$ and $\mathrm{B}$ ), we used a primer containing poly $\mathrm{dC}$ sequences $(7278)$ and a primer from the $B I K 1$ side of the DSB (7492); to examine DSB(R) (lanes 3 in A and B), we employed primer 7278 and a primer from the HIS4 side of the DSB (7680). The single bands in lanes 2 and 3 of A represent the PCR products containing sequences between the primers and the $X h o \mathrm{I}$ sites. The additional bands in lanes 2 and 3 of $B$ represent the PCR products containing sequences between the primers and the DSB-generated termini. Lane 1 contains marker DNA of 1-kb ladder (GIBCO BRL).

cells, in addition to the 700-bp fragment, we observed a fragment of $\sim 380$ bp (Figure 9B, lane 2). From our previous mapping analysis, this fragment had the expected size to represent the DSB. The detection of this fragment indicates that the DSBs result in $3^{\prime}$ termini with a hydroxyl group, since terminal transferase requires such a substrate (SAMBROOK et al. 1989).

The second set utilized the same poly $\mathrm{dC}$ primer and a primer derived from the HIS4 gene (primer 7680, described in MATERIALS AND METHODS). In DNA isolated from mitotic cells, a single 1300-bp fragment (the distance between the primer and the BIKI XhoI site) was observed (Figure 9A, lane 3), whereas in DNA isolated from meiotic cells, an additional 360-bp fragment was present (Figure 9B, lane 3). This PCR product was the size expected to represent the DSB (Figure 1).

The PCR products representing the DSBs were purified from the gel, cloned and sequenced. Since terminal transferase adds nucleotides to 3 ' termini, the sequences obtained represent $3^{\prime}$ break sites, with the first set of primers mapping $\mathrm{DSB}(\mathrm{L})$ and the second mapping $\operatorname{DSB}(\mathrm{R})$. The mapping of these breaks is summarized in Figure 10. Breaks representing DSB(R) were mapped in two independent experiments with upwardpointing arrows below the sequence representing the mapped sites. Since we cloned the DNA ends by addition of poly $\mathrm{dG}$, the position at the breakpoint is ambig-
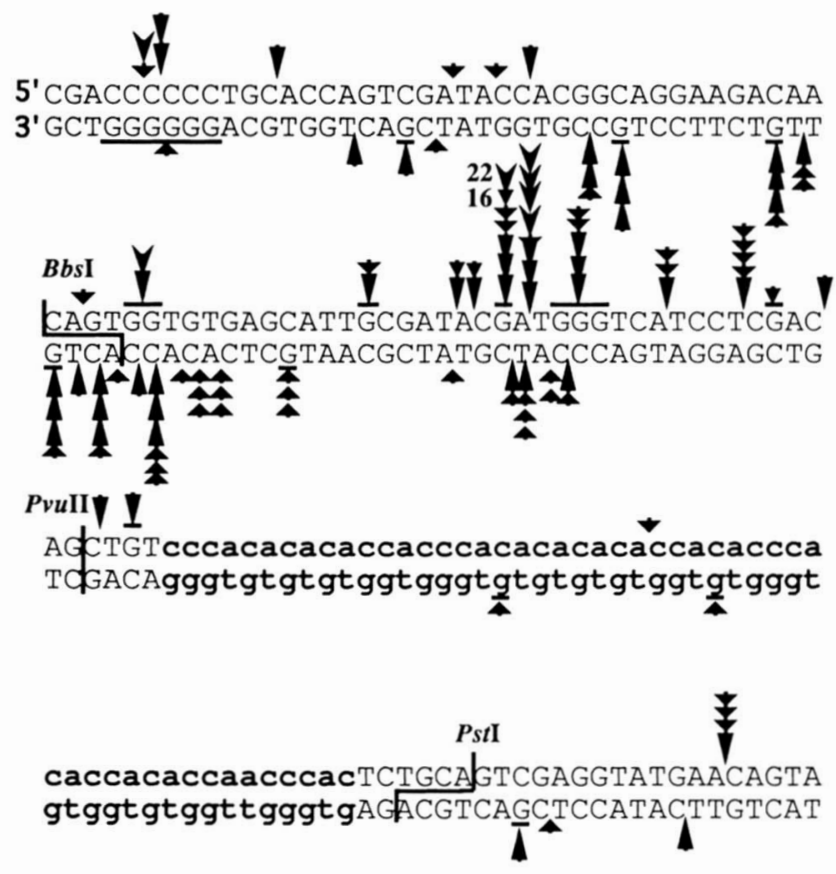

FIGURE 10.-Mapping of DSB sites using anchor-PCR. The meiosis-specific PCR fragments shown in Figure 9B were cloned and sequenced. Each arrow represents a single clone, except for the arrows marked 22 and 16 , which represent 22 and 16 clones with that breakpoint. Arrows with different shapes represent clones obtained in different experiments. Arrows above the line represent $3^{\prime}$ breaks in the upper strand (the $3^{\prime}$ termini of DSB(L)), and arrows below the line reflect $3^{\prime}$ breaks in the lower strand (the $3^{\prime}$ termini of $\operatorname{DSB}(\mathrm{R})$ ). Since the ends were defined by adding a poly $\mathrm{d} G$ tail to the termini, breakpoints mapping at Gs in the sequence are ambiguous. This ambiguity is indicated by horizontal lines above or below the sequence.

uous if it maps next to a $\mathrm{G}$ in the chromosomal sequence; such ambiguities are indicated by horizontal lines adjacent to the arrows in Figure 10. As expected from the other mapping study, most of the breaks were located on the BIKl side of the telomere insertion with few breaks within the telomere insertion. Sixty of sixtyfour sequenced clones for $\operatorname{DSB}(\mathrm{R})$ are shown in the figure; an additional four clones had breakpoints upstream and downstream of the sequences in Figure 10.

Mapping of breakpoints for DSB $(\mathrm{L})$ was done in four independent experiments. For two of these experiments, the distribution of breakpoints (indicated by downward-pointing arrows) was similar to that observed for DSB(R). In two experiments, however, most (about three-quarters) of the breakpoints mapped to a single site (indicated by numbers adjacent to arrows in Figure 10). From our previous mapping study, this site is frequently cleaved, but not substantially more than a number of other sites. In addition, no such strong DSB was observed with $\operatorname{DSB}(\mathrm{R})$. Thus, we believe the high frequency of recovery of breakpoints at this single site is an artifact. One possibility is that the end represented by this sequence is a better substrate for terminal transferase than the other ends. If this explanation is correct, however, this property must be very sensitive to subtle 
changes in experimental conditions, since this site was not strongly represented in two of the experiments. A second alternative is that DNA contamination occurred in two of the experiments. Although this alternative is difficult to rule out, the two experiments in which the site were overrepresented were done with completely different sets of solutions.

In summary, mapping by the PCR procedure is in reasonably good agreement with the previous mapping protocol. Since we found that the PCR procedure appeared to result in an artifactually strong site in two experiments, however, the direct blotting procedure is the method of choice in organisms with a high level of meiosis-specific DNA lesions. In organisms in which the level of DNA lesions is low, the PCR procedure is a reasonable alternative.

\section{DISCUSSION}

A telomere insertion upstream of HIS4 results in a very high level of meiotic recombination (WHITE et al. 1993) associated with a high level of DSB (FAN et al. 1995). The fine-structure mapping of the DSB indicates the following: (1) Most of the DSBs occur in a 50-bp region within the $B I K I$ gene adjacent to the telomeric sequences; DSBs do not occur in the telomeric sequences. (2) The DSB appears to involve a concerted cleavage of both strands to generate a blunt-ended DNA molecule, and (3) since the $3^{\prime}$ ends are substrates for terminal transferase, these termini have a $3^{\prime}$ hydroxyl group.

In yeast (WHITE et al. 1993; FAN et al. 1995), Caenorhabditis elegans (CANGIANO and LA VOLPE 1993), and mammalian cells (ALVAREz et al. 1993), interstitial telomeric sequences stimulate recombination and/or DSB formation. One interpretation of these effects is that these sequences are particularly susceptible to the endonuclease responsible for DSB formation. Our observation that DSBs are adjacent to rather than within the telomeric repeats rules out this interpretation. Our preferred model is that the hotspot activity of the telomeric sequences is related to the binding of the transcription factor Raplp. The 50-bp telomeric insertion contains three near consensus Raplp binding sites, and duplicated Raplp binding sites upstream of HIS4 strongly stimulate meiotic recombination (WHITE et al. 1993). We previously suggested that this stimulation is a consequence of Raplp binding increasing the accessibilty of meiotic chromatin to the meiotic endonuclease that causes the DSB or a consequence of local targeting of the endonuclease to the hotspot region by Raplp (FAN et al. 1995). By either of these mechanisms, the breaks could occur within the telomeric sequences or adjacent to these sequences.

In studies using DNase I and micrococcal nuclease on meiotic chromatin of the HIS4 region, we failed to find dramatic alterations in chromatin structure associated with different levels of hotspot activity (FAN and
Petes 1996). Consequently, we prefer the model that Raplp targets the meiotic nuclease to the chromatin, either directly or through bridging proteins. If this mechanism is correct, the targeting is sufficiently flexible that multiple sites of cleavage are allowed. Since the DSBs do not occur within the telomeric insertion or on the HIS4 side of the insert, cleavage may also be prevented by DNA binding proteins. By this model, a strong DSB site may require two properties, a binding site for a transcription factor and an adjacent sequence that is not protected by a DNA-binding protein.

Although we favor a model in which the positions of the cleavages are controlled by interactions of the endonuclease with transcription factors, we cannot rule out the possibility that the DSB sites are determined by accessibility of chromatin affected indirectly by transcription factor binding. Previous studies (OHTA et al. 1994; WU and LICHTEN 1994) at several recombination hotspots in yeast showed a correlation between nuclease-sensitive sites and hotspots for DSB formation. The nature of the correlation is that all hotspots for DSB formation appear in nuclease-sensitive regions, but not all nuclease-sensitive sites are hotspots for DSB formation (LIU et al. 1995; FAN and PETES 1996).

DSBs have been mapped at recombination hotspots in three previous studies (DE MASsY et al. 1995; LIU et al. 1995; Xu et al. 1995). In these studies, as in our study, DSB sites are distributed over a relatively small region $(<200 \mathrm{bp})$. The studies disagree about the nature of the termini produced by the break. LIU et al. (1995) concluded the termini have a two base 5 ' extension, and DE MAssy et al. (1995) found that the termini are blunt. This discrepancy could reflect different strain backgrounds, the different loci examined, or an experimental artifact. We have three independent arguments that the termini at the HIS4 locus do not have $5^{\prime}$ overhangs: (1) mixtures of $5^{\prime}$ and $3^{\prime}$ strands have no extra bands on sequencing gels, (2) DSB(L) and DSB(R) sites map to identical positions, and (3) the termini are sensitive to exonuclease III with or without treatment with $\alpha \mathrm{S}$ dNTPs. If the different termini detected in these studies do not represent an experimental artifact, then there is apparently more than one type of enzymatic activity that can produce DSBs in yeast. One interesting explanation of such a difference is that different transcription factors may target different endonucleases to hotspot regions.

We thank QINGQING FAN and DAVID KIRKPATRICK for frequent discussions concerning the research and for comments on the manuscript. We thank S. PORTER, D. NAG, and M. WHITE for strains or plasmids and M. LICHTEN for advice on mapping protocols. The research was supported by the National Institutes of Health (GM24110 ).

\section{LITERATURE CITED}

AI_ANI, E., R. PADMORE and N. KLECKNER, 1990 Analysis of wild-type and rad50 mutants of yeast suggests an intimate relationship between meiotic chromosome synapses and recombination. Cell 61: $419-436$. 
Alvarez, L., J. W. Evans, R. Wilks, J. N. Lucas, J. M. Brown et al., 1993 Chromosomal radio sensitivity at intrachromosomal telomeric sites. Genes Chromosomes Cancer 8: 8-14.

Ausubei, F. M., R. Brent, R. E. Kingston, D. D. Moore, J. G. Seid MAN et al., 1993 Current Protocols in Molecular Biology. Vol. I: 3.17.4. John Wiley \& Sons, New York.

Bish(OP, D. K, D. PARK, L. XU and N. KIECKNER, 1992 DMC1: a meiosis-specific yeast homolog of E. coli recA required for meiotic recombination, synaptonemal complex formation and cell cycle progression. Cell 69: $439-456$.

Bollum, F. J., 1974 Terminal deoxynucleotidyl transferase, pp. $145-171$ in The Enzymes, Vol. 10, edited by P. D. Boyer. Academic Press, New York.

BrutlaG, D., and A. Kornberg, 1972 Enzymatic synthesis of deoxyribonucleic acid. J. Biol. Chem. 247: 241-248.

Cangiano, G., and A. LA Volpe, 1993 Repetitive DNA sequences located in the terminal portion of the Canenorhabditis elegans chromosomes. Nucleic Acids Res. 21: 1133-1139.

CAO, L., E. AI ANI and N. KLECKNER, 1990 A pathway for generation and processing of double-strand breaks during meiotic recombination in S. cerevisiae. Cell 61: 1089-1101.

Church, G. M., and W. Gilbert, 1984 Genomic sequencing. Proc. Natl. Acad. Sci. USA 81: 1991-1995.

DE MASSY, B., and A. NICOI AS, 1993 The control in cis of the position and amount of the $A R G 4$ meiotic double-strand break of Saccharomyces cerevisiae. EMBO J. 12: 1459-1466.

DE MASsY, B., V. RoCCO and A. NICOLAS, 1995 The nucleotide mapping of DNA double-strand breaks at the CYS 3 initiation site of meiotic recombination in Saccharomyces cerevisiae. EMBO J. 14: $4589-4598$.

FAN, Q., and T. Petes, 1996 Relationship between nuclease hypersensitive sites and meiotic recombination hotspot activity at the HIS4 locus of Saccharomyces cerevisiae. Mol. Cell. Biol. (in press).

FAN, Q, F. XV and T. Pftrs, 1995 Meiosis-specific double-strand breaks at the HIS4 recombination hot spot in the yeast Saccharomyces cerevisiae: control in cis and trans. Mol. Cell. Biol. 15: 16791688.

Frohman, M. A., M. K. Dush and G. R. MARTIN, 1988 Rapid production of full-length cDNA from rare transcripts: amplification using a single gene-specific oligonucleotide primer. Proc. Natl. Acad. Sci. USA 85: 8998-9002.

GAME, J. C., 1993 Pulsed-field gel analysis of pattern of DNA doublestrand breaks in the Saccharomyces cerevisiae genome during meiosis. Dev. Genet. 13: 485-497.

Hemsley, A., N. Arnheim, M. D. Toney, G. Cortopassi and D. J. GALAS, 1989 A simple method for site-directed mutagenesis using the polymerase chain reaction. Nucleic Acids Res. 17: 65456551.

HENIKOFF, S., 1984 Unidirectional digestion with exonuclease III creates targeted breakpoints for DNA sequencing. Gene 28: $351-359$.

HUibRegtSe, J. M., and D. R. ENGELKE, 1991 Direct sequence and footprint analysis of yeast DNA by primer extension. Methods Enzymol. 194: 550-562.

KeEneY, S., and N. KLECKNER, 1995 Covalent protein-DNA complexes at the $5^{\prime}$ strand termini of meiosis-specific double-strand breaks in yeast. Proc. Natl. Acad. Sci. USA 92: 11274-11278.

LichTEN, M., and A. S. H. Goldman, 1995 Meiotic recombination hotspots. Annu. Rev. Genet. 29: 423-444.

LiU, J., T.C. WU and M. LiCHTEN, 1995 The location and structure of double-strand breaks induced during yeast meiosis: evidence for a covalently linked DNA-protein intermediate. EMBO J. 14: $4599-4608$.

NAG, D. K, and T. D. Petes, 1993 Physical detection of heteroduplexes during meiotic recombination in the yeast Saccharomyces cerevisiae. Mol. Cell. Biol. 13: 2324-2331.

NAG, D. K., M. A. White and T. D. Petes, 1989 Palindromic sequences in heteroduplex DNA inhibit mismatch repair in yeast. Nature 340: 318-320.

OHTA, K. T. Shibata and A. Nicolas, 1994 Changes in chromatin structure at recombination initiation sites during yeast meiosis. EMBO J. 13: $5754-5763$.

PADMORE, R., L. CAO and N. KLECKNER, 1991 Temporal comparison of recombination and synaptonemal complex formation during meiosis in S. cerevisiae. Cell 66: 1239-1256.

Petes, T. D., R. E. Malone and L. S. Symington, 1991 Recombination in yeast, pp. 407-521 in The Molecular and Cellular Biology of the Yeast Saccharomyces, Vol. 1, edited by J. R. BROACH, E. W. JONES and J. R. PRINGLE. Cold Spring Harbor Laboratory Press, Cold Spring Harbor, NY.

Pluta, A. F., and V. A. ZAKIAN, 1989 Recombination occurs during telomere formation in yeast. Nature 337: 429-433.

Putney, S. D., S. J. Benkovic and P. SChimmel, 1981 A DNA fragment with an $\alpha$-phosphorothioate nucleotide at one end is asymmetrically blocked from digestion by exonuclease III and can be replicated in zivo. Proc. Natl. Acad. Sci. USA 78: 7350-7354.

SAMBROOK, J., E. FrITSCH and T. MANIATIS, 1989 Molecular Cloning: A Laboratory Manual. Cold Spring Harbor Laboratory Press, Cold Spring Harbor, NY.

STURZL, M., and W. K. RoTH, 1990 "Run-off" synthesis and application of defined single-stranded DNA hybridization probes. Anal. Biochem. 185: 164-169.

Sun, H., D. Treco, N. P. Schultes and J. W. Szostak, 1989 Doublestrand breaks at an initiation site for meiotic gene conversion. Nature 338: 87-90.

Sun, H., D. Treco and J. W. Szostak, 1991 Extensive 3'-overhanging, single-stranded DNA associated with the meiosis-specific double-strand breaks at the ARG4 recombination initiation site. Cell 22: 1155-1161.

White, M. A., M. Wierde, P. Detloff and T. D. Petes, 1991 DNA binding protein RAP1 stimulates meiotic recombination at the HIS4 locus in yeast. Proc. Natl. Acad. Sci. USA 88: 9755-9759.

White, M. A., P. Detloff, M. Strand and T. D. Petes, 1992 A promoter deletion reduces the rate of mitotic, but not meiotic recombination at the HIS4 locus in yeast. Curr. Genet. 21: $109-116$.

White, M. A., M. Dominska and T. D. Petes, 1993 Transcription factors are required for the meiotic recombination hotspot at the HIS4 locus in Saccharomyces cerevisiae. Proc. Natl. Acad. Sci. USA 90: $6621-6625$.

WU, T. C., and M. LICHTEN, 1994 Meiosis-induced double-strand break sites determined by yeast chromatin structure. Science 263: 515-518.

XU, L., and N. KL.ECKNER, 1995 Sequence non-specific doublestrand breaks and interhomology interactions prior to doublestrand break formation at a meiotic recombination hot spot in yeast. EMBO J. 16: 5115-5128.

ZenvirTh, D., T. Arbel, A. Sherman, M. Goldway, S. Kuein et al., 1992 Multiple sites for double-strand breaks in whole meiotic chromosomes of Saccharomyces cerevisiae. EMBO J. 11: 3441-3447. 